\title{
Designing and Implementation of Algorithms on MATLAB for Adaptive Noise Cancellation from ECG Signal
}

\author{
Hemant Kumar Gupta \\ JECRC UDML College of Engineering, \\ Jaipur, Rajasthan, India - 302022
}

\author{
Ritu Vijay,Ph.D \\ Banasthali University, \\ Banasthali,Jaipur, Rajasthan,
}

\author{
Neetu gupta \\ Rajasthan College of Engineering \\ for Women , Jaipur, Rajasthan
}

\begin{abstract}
The medical monitoring devices are more sensitive for the biomedical signal recording and need more accurate results for every diagnosis. The low frequency signal is destroyed by power line interference of $50 \mathrm{~Hz}$ noise, this noise is also source of interference for biomedical signal recording. The frequency of power line interference $50 \mathrm{~Hz}$ is nearly equal to the frequency of ECG, so this $50 \mathrm{~Hz}$ noise can destroyed the output of ECG signal. One way to remove the noise is to filter the signal with a notch filter at $50 \mathrm{~Hz}$. However, due to slight variations in the power supply to the hospital, the exact frequency of the power supply might (hypothetically) wander between $47 \mathrm{~Hz}$ and $53 \mathrm{~Hz}$. A static filter would need to remove all the frequencies between 47 and $53 \mathrm{~Hz}$, which could excessively degrade the quality of the ECG since the heart beat would also likely have frequency components in the rejected range. To circumvent this potential loss of information, an adaptive filter has been used. The adaptive filter would take input both from the patient and from the power supply directly and would thus be able to track the actual frequency of the noise as it fluctuates [2].
\end{abstract}

\section{Keywords:}

Biomedical signals, Physiological, signal Processing, EMG Signals, Diagnostic Instrumentation.

\section{INTRODUCTION}

The electrocardiograph (ECG) is an instrument, which records the electrical activity of the heart. ECG provides valuable information about the wide range of the cardiac disorders such as the presence of an inactive part or an enlargement of heart muscle. ECG is used in characterization laboratory, coronary care unit and for routing diagnostic application in cardiology. Although the electric field generated by the heart can be best characterized by vector quantity, its generally convenient to directly measured only scalar quantity, a voltage difference of $\mathrm{mV}$ order between the given point of the body. Most of the electrophysiological signals have frequencies between dc $(0$ $\mathrm{Hz}$ ) and $3000 \mathrm{~Hz}$ and amplitudes ranging between 10 microvolt's and 10 milli-volts [3][1] as shown in Table 1, below.

Table 1 Electrophysiological Signals

\begin{tabular}{|l|l|l|l|}
\hline Signal & $\begin{array}{l}\text { Biological } \\
\text { source }\end{array}$ & $\begin{array}{l}\text { Average } \\
\text { amplitude }\end{array}$ & Frequency \\
\hline $\begin{array}{l}\text { Electrocardiogram } \\
\text { (ECG) }\end{array}$ & Heart & $1-5 \mathrm{mV}$ & $\begin{array}{l}0.05-100 \\
\mathrm{~Hz}\end{array}$ \\
\hline $\begin{array}{l}\text { Electroencephalogra } \\
\mathrm{m} \text { (EEG) }\end{array}$ & Brain & $10-50 \mu \mathrm{V}$ & $0-150 \mathrm{~Hz}$ \\
\hline $\begin{array}{l}\text { Electromyogram } \\
\text { (EMG) }\end{array}$ & Muscles & $0.1-1 \mathrm{mV}$ & $40-3000 \mathrm{~Hz}$ \\
\hline $\begin{array}{l}\text { Electrooculogram } \\
\text { (EOG) }\end{array}$ & Eyeball & $\begin{array}{l}0.05-3.5 \\
\mathrm{mV}\end{array}$ & $0-125 \mathrm{~Hz}$ \\
\hline
\end{tabular}

The amplifier and writing part should fatefully reproduce signal in this range. A good low frequency response is essential to ensure the stability of baseline. Due to their low levels and their frequency spectra, these signals can be easily swamped out by noise pick-ups from the power lines So before these signals can be further processed to establish the diagnostic values, their signal-to-noise ratio must be improved by removing the contaminating $50 \mathrm{~Hz}$ interference from the power line.

Since there is a spectral overlap between the desired signals and interfering $50 \mathrm{~Hz}$ from electric power system, the removal of power line interference must be such that the diagnostic information in the frequency range around $50 \mathrm{~Hz}$ is less affected.

Significant Features of ECG Waveform: A typical scalar electrocardiographic lead is shown in Fig.1, where the significant features of the waveform are the $\mathrm{P}, \mathrm{Q}, \mathrm{R}, \mathrm{S}$, and $\mathrm{T}$ waves, the duration of each wave, and certain time intervals such as the P-R, S-T, and Q-T intervals. ECG signal is periodic with fundamental frequency determined by the heartbeat. Each significant feature of ECG signal can be represented by shifted and scaled versions one of these waveforms as shown below [4].

- $\quad$ QRS, Q and S portions of ECG signal can be represented by triangular waveforms.

- $\quad \mathrm{P}, \mathrm{T}$ and $\mathrm{U}$ portions can be represented by triangular waveforms.

Once each of these portions generated, they can be added finally to get the ECG signal. So the generated output ECG signal by MATLAB is shown in Fig. 2 .

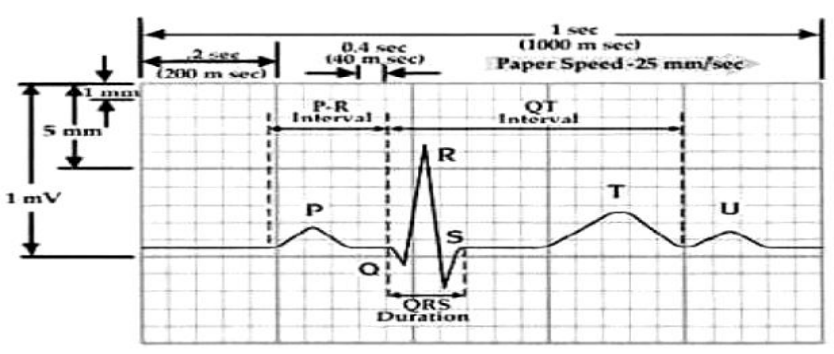

Fig.1 Typical one-cycle ECG signal 


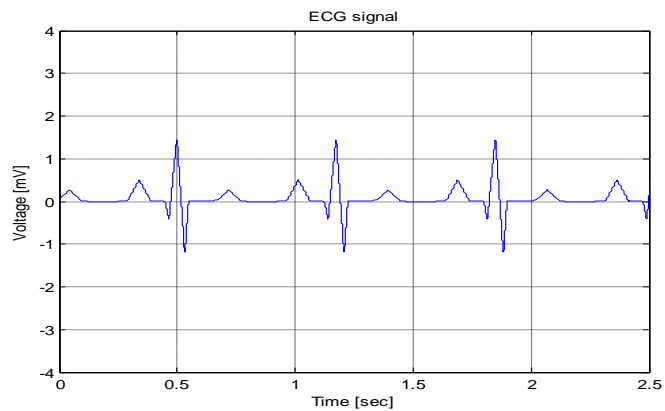

Fig.2 Typical ECG output waveform simulated in MATLAB

\section{Objective}

This study mainly deals with the various aspects of Adaptive Noise Cancellation and usage in different applications. The major objectives of this thesis can be listed as follow:

- This task involves the study of the principle of Adaptive Noise Cancellation and its Applications.

- Cancellation of Electric power noise $(50 \mathrm{~Hz})$ from ECG signal by the designing and implementation of different adaptive algorithms based upon FIR filters using MATLAB software [6].

- The LMS algorithm can be easily modified to normalized step-size version known as the normalized LMS algorithm. NLMS, not only provides a potentially faster adaptive algorithm, but also guarantee a more stable convergence response to variation of input signal power

\section{Basic Structure of an Adaptive Filter}

An adaptive is essentially a digital filter with self adjustment characteristics. It consist of two distinct part a digital filter with adjustable coefficient, and an adaptive algorithm, which is used to adjust or modify the coefficient of the filter as shown in Fig 3 where two input signal $d(n)$ and $u(n)$ are applied simultaneously to the adaptive filtering system. The signal $d(n)$ is measured signal obtained using some sensor (also called desired signal) and it is contaminated signal containing both the actual signal and noise and interference signal, assumed uncorrelated with each other. The signal u(n) is reference input signal and is also obtained using some sensor and it provide a measure of the contaminating signal which is correlated in some way with noise and interference in the measured signal.

In most adaptive system, digital filter used is FIR because of simplicity and guaranteed stability. Mostly FIR filter is implemented using direct form structure. However, lattice structure is preferred in some application like speech signal processing. The filter coefficient at time $\mathrm{n}$ is given by vector w (n) of length M, where M represents length of FIR filter. As filter is $M$ tap, we consider $M$ sample of input $u(n)$ at time $n$ as another vector $\mathrm{u}(\mathrm{n})$ of $\mathrm{M}$.

We can write

$$
\begin{aligned}
& \mathrm{W}(\mathrm{n})=\left[\mathrm{w}_{0}(\mathrm{n}) \mathrm{w}_{1}(\mathrm{n}) \ldots \ldots \mathrm{w}_{\mathrm{M}-1}(\mathrm{n})\right]^{\mathrm{T}} \\
& \mathrm{u}(\mathrm{n})=[\mathrm{u}(\mathrm{n}) \mathrm{u}(\mathrm{n}-1) \ldots \ldots \mathrm{u}(\mathrm{n}-\mathrm{M}+1)]
\end{aligned}
$$

The output filter

$$
y(n)=\sum_{i=0}^{M-1} w_{i}(n) u(n-i)=w^{T}(n) u(n)
$$

(3)

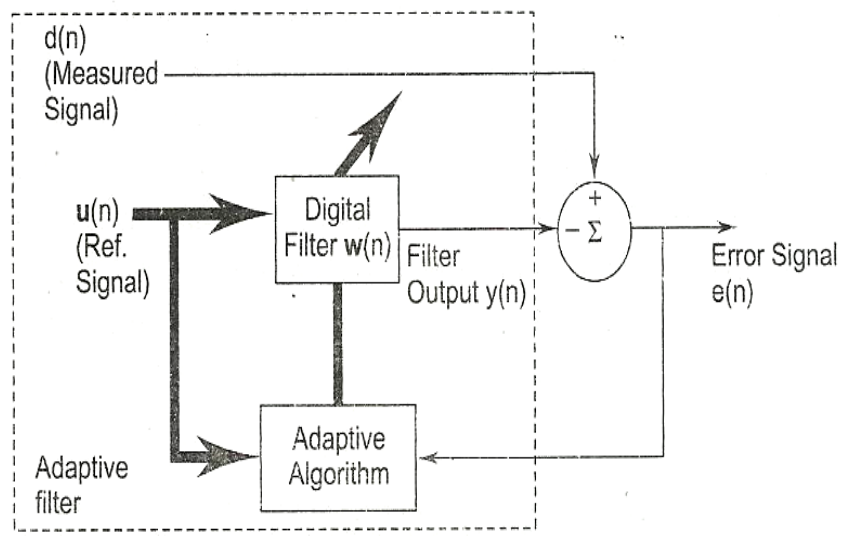

Fig. 3 Block diagram of an adaptive filter

Adaptive Algorithm

\section{Least Mean Square (LMS) Algorithm}

The LMS is an approximation of the steepest descent algorithm, which uses an instantaneous estimate of the gradient vector. The estimate of the gradient is based on sample values of the tap input vector and an error signal. The algorithm iterates over each tap weight in the filter, moving it in the direction of the approximated gradient. The idea behind LMS filters is to use the method of steepest descent to find a coefficient vector $n w$ which minimizes a cost function [8][23].

The LMS algorithm can be explain as

The output y (n) of FIR filter structure can be obtained from

$y(n)=\sum_{m=0}^{N-1} w(m) u(n-m)$

Where $\mathrm{n}$ is no. of iteration

The error signal calculated by Eq. (5.5)

$$
e(n)=d(n)-y(n)
$$

The filter weights are updated from the error signal e (n) and input signal $u(n)$ as in Eq. (5.6)

$$
\mathrm{w}(\mathrm{n}+1)=\mathrm{w}(\mathrm{n})+\mu \mathrm{e}(\mathrm{n}) \mathrm{u}(\mathrm{n})
$$

where $w(n)$ is the current weight value vector, $w(n+1)$ is the next weight value vector, $u(n)$ is the input signal vector, $e(n)$ is the filter error vector and $\mu$ is the convergence factor which determine the filter convergence speed and overall behavior [11].

\section{LMS Algorithm}

In practical application of adaptive filtering, a fixed step size Algorithm is required for

(i) Easier implementation

(ii) Single adjustable parameters $\mu$ for controlling the convergence rate but slow convergence.

\section{Normalized LMS (NLMS) Algorithm}

Normalized Least Mean Square (NLMS) is actually derived from Least Mean Square (LMS) algorithm. The need to derive this NLMS algorithm is that the input signal power changes in time and due to this change the step-size between two adjacent coefficients of the filter will also change and also affect the convergence rate. Due to small signals this convergence rate will slow down and due to loud signals this convergence rate will increase and give an error. So to overcome this problem, try to adjust the step-size parameter with respect to the input signal power. Therefore the step-size parameter is said to be normalized. When design the LMS adaptive filter, one difficulty we meet is the selection of the step-size parameter $\mu$. The main drawback of the pure LMS 
algorithm is that it is sensitive to the scaling of its input $\mathrm{u}(n)$. This makes it very hard to choose a learning rate $\mu$ that guarantees stability of the algorithm [25]

When the convergence factor $\mu$ is large, the algorithm experiences a gradient noise amplification problem. In order to solve this difficulty, the NLMS (Normalized Least Mean Square) algorithm is used. The correction applied to the weight vector $\mathrm{w}(\mathrm{n})$ at iteration $\mathrm{n}+1$ is "normalized" with respect to the squared Euclidian norm of the input vector $\mathrm{u}(\mathrm{n})$ at iteration $\mathrm{n}$. We may view the NLMS algorithm as a timevarying step-size algorithm, calculating the convergence factor $\mu$ as in Eq.5.7

$$
\mu(n)=\frac{\alpha}{c+\square u(n) \square^{2}}
$$

(7)

where $\alpha$ is the NLMS adaption constant, which optimize the convergence rate of the algorithm and should satisfy the condition $0<\alpha<2$, and $c$ is the constant term for normalization and is always less than 1 . The Filter weights are updated by the

Eq.

$$
w(n+1)=w(n)+\frac{\alpha}{c+\square u(n) \square^{2}} e(n) u(n)
$$

(8)

Normalization algorithm results in smaller step size values than the conventional LMS algorithm. The normalized algorithm usually converges faster than the LMS algorithm, since it utilizes a variable convergence factor aiming at the minimization of the instantaneous output error.

\section{Comparison between LMS \& NLMS}

ECG signals which are generated contain noise signal. To reduce these noise signals LMS algorithm and NLMS algorithm are used. Here two algorithms are studied and output results for noise cancelling are shown in Fig. 4 \& Table 2. It is clear that these algorithms remove the noise efficiently present in the ECG signal and the performance of NLMS is better

than

LMS.

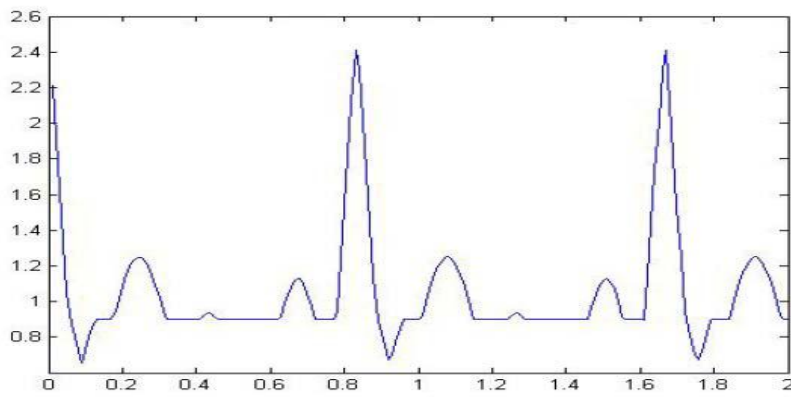

(a) (b)
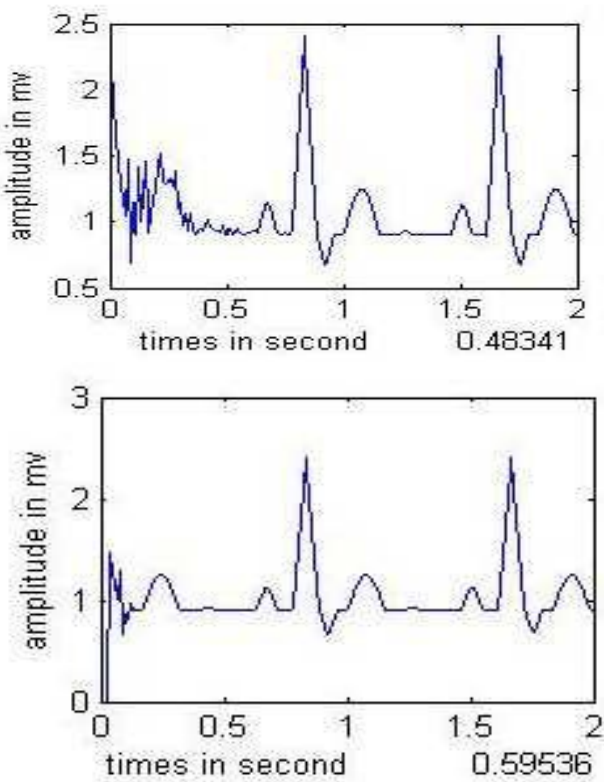

(c)

Fig. 4 (a) ECG signal (b) LMS algorithm (c) NLMS algorithm

Table 2 Summary of ECG noise cancellation

\begin{tabular}{|c|l|l|}
\hline $\begin{array}{c}\text { S. } \\
\text { No. }\end{array}$ & Algorithm & $\begin{array}{l}\text { Percentage of noise } \\
\text { cancellation }\end{array}$ \\
\hline 1 & LMS & $48.34 \%$ \\
\hline 2 & NLMS & $59.54 \%$ \\
\hline
\end{tabular}

Flowchart of the NLMS algorithm

The flowchart of the NLMS algorithm is very important for us to orient all steps we need to do in the simulation. This is shown in the figure 5 given below.

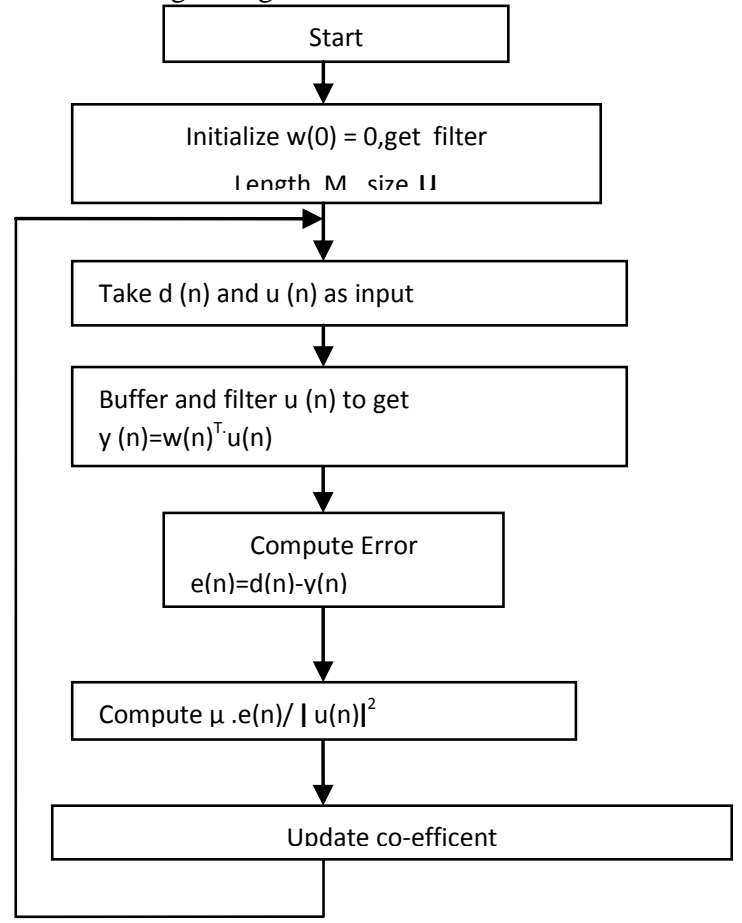

Fig. 5 Flowchart of NLMS algorithm 


\section{Adaptive Filter Algorithms}

In these code segments, the purpose need to obtain is processing and performing the LMS and NLMS algorithms.

The comparison below between the theories the simulation parts (MATLAB code) may bring the better understanding about not only the algorithm but the programming work.

The summary of the algorithms (LMS, NLMS) and the code segments are demonstrated in the given below.

\section{SIMULATION:}

\section{Implementations of LMS Algorithm:}

- Initialization: If prior knowledge of the tap weight vector $\mathrm{w}(\mathrm{n})$ is available, use it to select an appropriate value for $\mathrm{w}(\mathrm{n})$, otherwise, set $\mathrm{w}(0)=0$. Take, $0<\mathrm{u}<\left(1 / \mathrm{M}, \mathrm{S}_{\max }\right)$ Where: $\mathrm{S}_{\max }=$ the maximum value of PSD of the tap input $u(n)$

- Data:

$$
\text { Give } \quad \mathrm{u}(\mathrm{n})=\mathrm{M} \text { by } 1 \text { tap input vector at }
$$

time $n$,

$$
\mathrm{d}(\mathrm{n})=\text { desired response at time } \mathrm{n}
$$

To be computed: $\quad \mathrm{w}(\mathrm{n})=$ estimate of tap-weight vector at time $\mathrm{n}$

- Computation:

$$
\begin{gathered}
y(n)=w(n) \cdot u(n) \\
e(n)=d(n)-y(n) \\
w(n+1)=w(n)+\mu . e(n) \cdot u(n)
\end{gathered}
$$

\begin{tabular}{|c|c|c|c|c|}
\hline S. & \multicolumn{2}{|r|}{ LMS algorithm } & \multirow{2}{*}{\multicolumn{2}{|c|}{$\begin{array}{l}\text { The algorithm required } 2 * \mathrm{M}+1 \text { addition and } 2 * \mathrm{M}+1 \\
\text { multiplication at any iteration } \mathrm{n} \text { where } \mathrm{M} \text { is the tap length or } \\
\text { filter order. The computation complexity depends on the } \\
\text { order of the filter and it must be carefully chosen. The } \\
\text { following figure shown the flow chart to implement the } \\
\text { algorithm } \\
\text { Table } 4 \text { Normalized Least Mean Square (NLMS) } \\
\text { algorithm }\end{array}$}} \\
\hline \multirow[t]{2}{*}{1} & \multirow[t]{2}{*}{$\begin{array}{l}\text { Initial Conditions } \\
:\end{array}$} & $\begin{array}{ll}0<\mu<1 & \\
\text { Length of } & \text { Adaptive } \\
\text { filter=L } & \\
\text { Input } & \text { vector: } \\
\mathrm{u}[0,0,0 \ldots 0]^{\mathrm{T}} & \\
\text { Wight } & \text { vector: }\end{array}$ & & \\
\hline & & $\mathrm{w}[0,0,0 \ldots 0]^{\mathrm{T}} \quad \mathrm{S} . \mathrm{N \phi}$ & \multicolumn{2}{|c|}{ 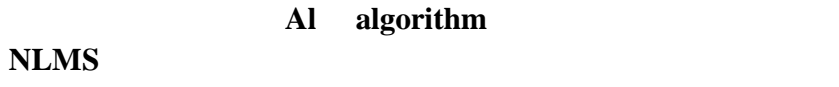 } \\
\hline & \multicolumn{2}{|c|}{$\begin{array}{l}\text { For each instant }=1,2,3 \ldots, \text { compute: } 1 \\
\text { of time, } \mathrm{n}=1, \\
2, \ldots, \text { compute: }\end{array}$} & \multirow[t]{3}{*}{ Initial Conditions: } & \multirow{3}{*}{$\begin{array}{l}0<\alpha<2 \text { and } \mathrm{c} \text { is small constant. } \\
\text { Length of Adaptive filter }=\mathrm{L} \\
\text { Input vector: } \mathrm{u}[0,0,0 \ldots 0]^{\mathrm{T}} \\
\text { Wight vector: } \mathrm{w}[0,0,0 \ldots 0]^{\mathrm{T}}\end{array}$} \\
\hline 2 & Output signal: & $y(n)=w^{T} \cdot u(n)$ & & \\
\hline 3 & Estimation Error: & $\mathrm{e}(\mathrm{n})=\mathrm{d}(\mathrm{n})-\mathrm{y}(\mathrm{n})$ & & \\
\hline 4 & $\begin{array}{l}\text { Tap-Weight } \\
\text { Adaptation: }\end{array}$ & $\begin{array}{l}w(n+1)=w+2 \mu \\
. e(n) \cdot u(n) ;\end{array}$ & \multicolumn{2}{|c|}{ For each instant of time, $\mathrm{n}=1,2, \ldots$, compute: } \\
\hline & & $.0(11) \cdot 4(I I)$ & Output signal: & $\mathrm{y}(\mathrm{n})=\mathrm{w}^{\mathrm{T}} \cdot \mathrm{u}(\mathrm{n})$ \\
\hline \multirow{2}{*}{\multicolumn{3}{|c|}{$\begin{array}{l}\text { lementations of NLMS Algorithm } \\
\text { tandard form of least mean square (LMS) filte } \frac{3}{\mathrm{r}} 4^{\text {in }} \\
\text { stment applied to the tap weight vector of the filter at } \\
\text { tion n consist of product of three terms: }\end{array}$}} & Estimation Error: & $\mathrm{e}(\mathrm{n})=\mathrm{d}(\mathrm{n})-\mathrm{y}(\mathrm{n})$ \\
\hline & & & adaption step size: & $\begin{array}{l}w(n)+\left[2 \alpha / c+u(n)^{T} \cdot u(n)\right] e(n) u(n) \\
w(n+1)=w+2 \mu \cdot e(n) \cdot u(n)\end{array}$ \\
\hline
\end{tabular}

Table 3 Least Mean Square (LMS) algorithm

important technique for optimizing speed of convergence while maintaining the adjustment applied to tap weight vector at iteration $\mathrm{n}+1$ is 'normalized' with respect to the squared Euclidean norm of the tap -input vector $\mathrm{u}(\mathrm{n})$ at iteration $\mathrm{n}-$ hence the term "normalized". It can be briefly described as follows:

- Initialization: If prior knowledge of the tap weight vector $\mathrm{w}(\mathrm{n})$ is available, use it to select an appropriate value for $\mathbf{w}(0)$, otherwise set $\mathbf{w}(0)=0$.

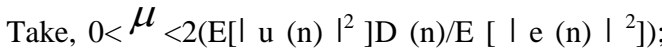
where, $E\left[|\mathrm{u}(\mathrm{n})|^{2}\right]$ = input signal power , $E[\mathrm{l}$ e (n) $\left.{ }{ }^{2}\right]=$ error signal power, D (n) mean square deviation of weight vector

- Data :

Given $\quad \mathrm{u}(\mathrm{n})=\mathrm{M}$ by 1 tap input vector at time $\mathrm{n}$. $\mathrm{d}(\mathrm{n})=$ desired response at time $\mathrm{n}$.

To be computed $\mathbf{w}(\mathrm{n})=$ estimate of tap-weight vector at time $\mathrm{n}$.
- Computation: $\mathrm{y}(\mathrm{n})=\mathbf{w}(\mathrm{n})^{\mathrm{T}} . \mathbf{u}(\mathrm{n})$ $\mathrm{e}(\mathrm{n})=\mathrm{d}(\mathrm{n})-\mathrm{y}(\mathrm{n})$

$$
\mathbf{w}(\mathrm{n}+\mathbf{1})=\mathbf{w}(\mathrm{n})+\mu \text {.e (n).u (n) }{ }^{\square} \mathrm{u}(\mathrm{n}){ }^{\square}
$$

The algorithm required $2 * \mathrm{M}+1$ addition and $2 * \mathrm{M}+1$ multiplication at any iteration $\mathrm{n}$ where $\mathrm{M}$ is the tap length or filter order. The computation complexity depends on the

Table 4 Normalized Least Mean Square (NLMS)

NLMS designer's control.

(ii) The tap input vector $\mathrm{u}(\mathrm{n})$, which is supplied by a source of information.

(iii) The estimation error $\mathrm{e}(\mathrm{n})$, which is calculated at iteration $\mathrm{n}$.

The adjustment is directly proportional to the tap input vector $\mathrm{u}(\mathrm{n})$. Therefore, when $\mathrm{u}(\mathrm{n})$ is large, the LMS filter suffer from gradient noise amplification problem. Also, the maximum step size $u$ guarantee stability signal, $u(n)$. One 


\section{Results:}

LMS algorithm: In this case $\mu=0.05$, Filter length is 15,20 , 25 and 1400 iterations Fig. 6, 7, 8 given below.
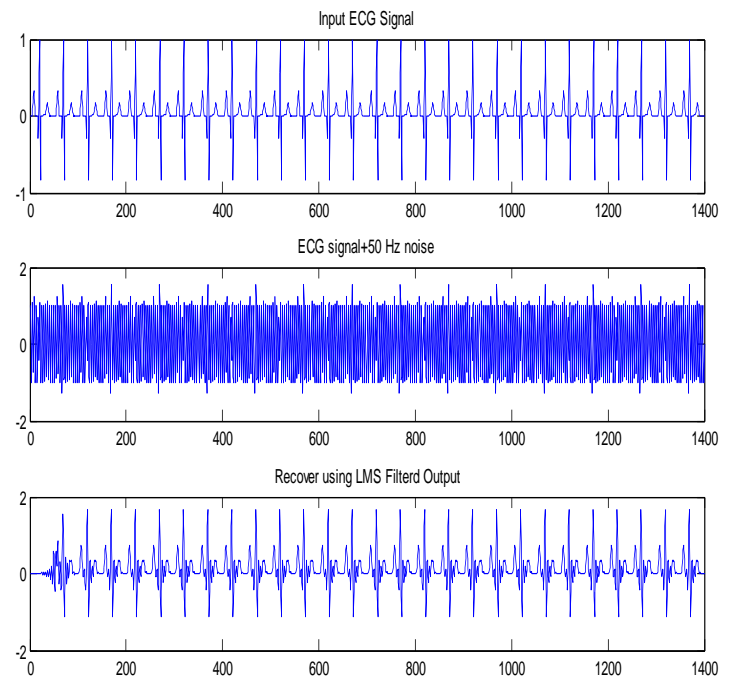

Figure 6 LMS algorithm where $\mu=0.05$, Filter length $=15$
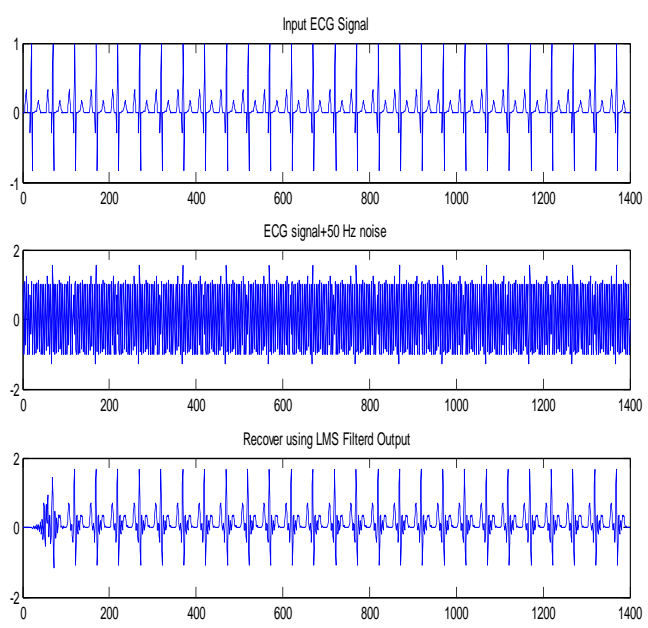

Fig.7 LMS algorithm where $\boldsymbol{\mu}=\mathbf{0 . 0 5}$, Filter length $=\mathbf{2 0}$
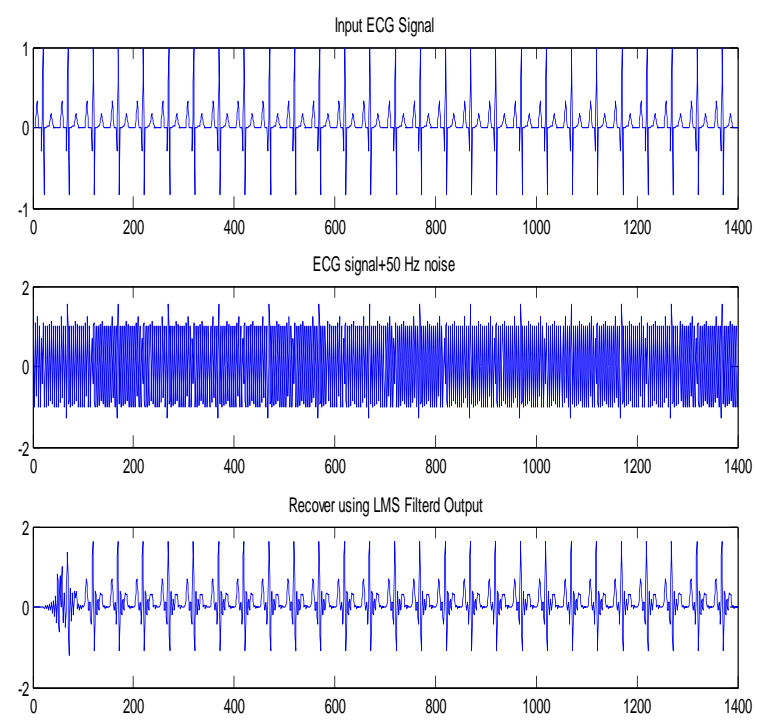

Fig. 8 LMS algorithm where $\mu=0.05$, Filter length $=25$

LMS algorithm: In this case $\mu=0.09$, Filter length is 15,20 , 25, 35 and 1400 iterations Fig. 9, 10, 11 given below.
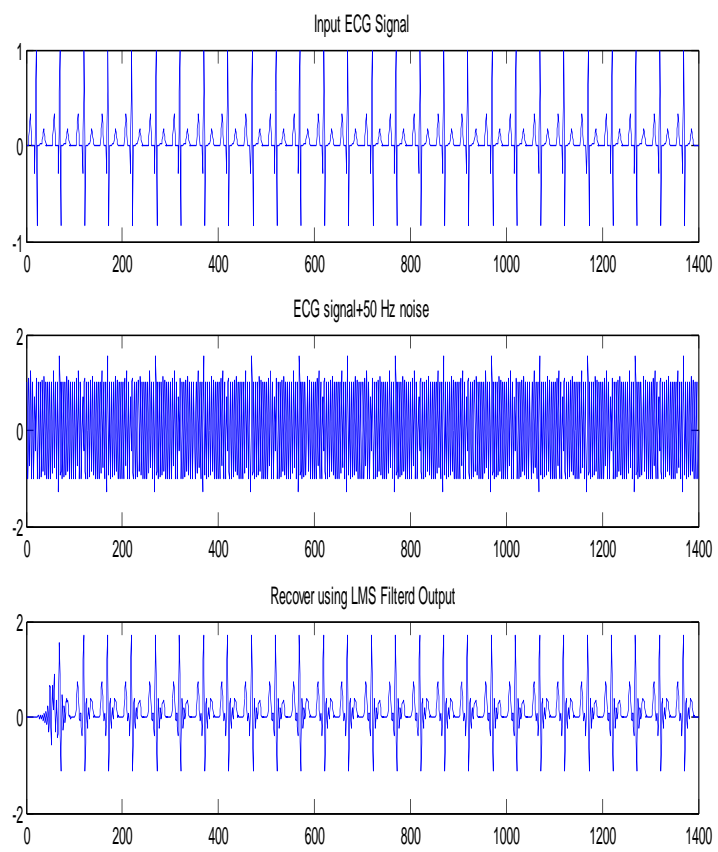

Fig. 9 LMS algorithm where $\mu=0.09$, Filter length $=$ 

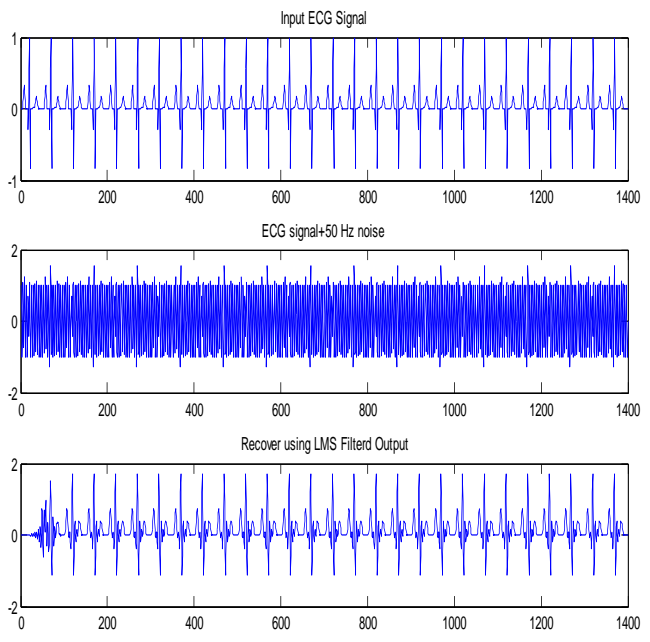

Fig. 10 LMS algorithm where $\mu=0.09$, Filter length $=$ 20
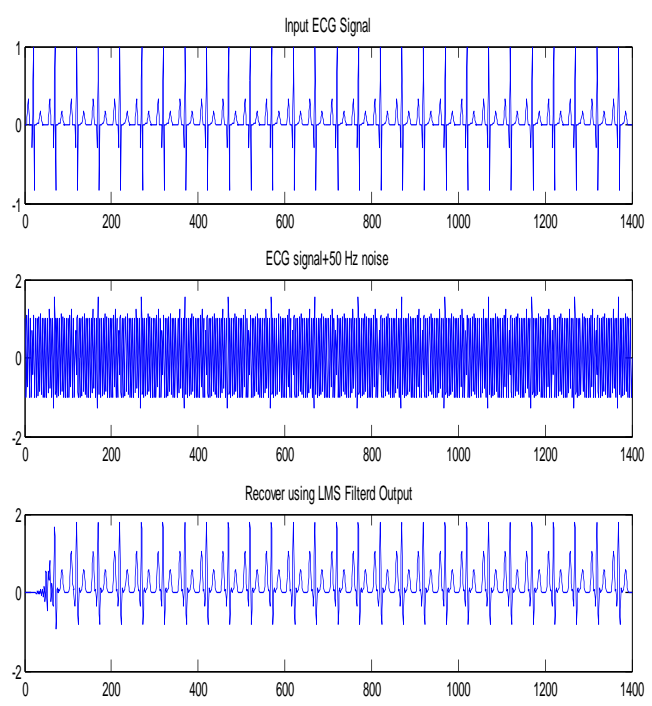

Fig. 11 LMS algorithm where $\mu=0.09$, Filter length $=25$

NLMS algorithm: In this case $\mathrm{c}=0.019, \alpha=0.102$, Filter length is $15,20,25,30,35$ and 1400 iterations Fig. 12, 13 shown in given below.
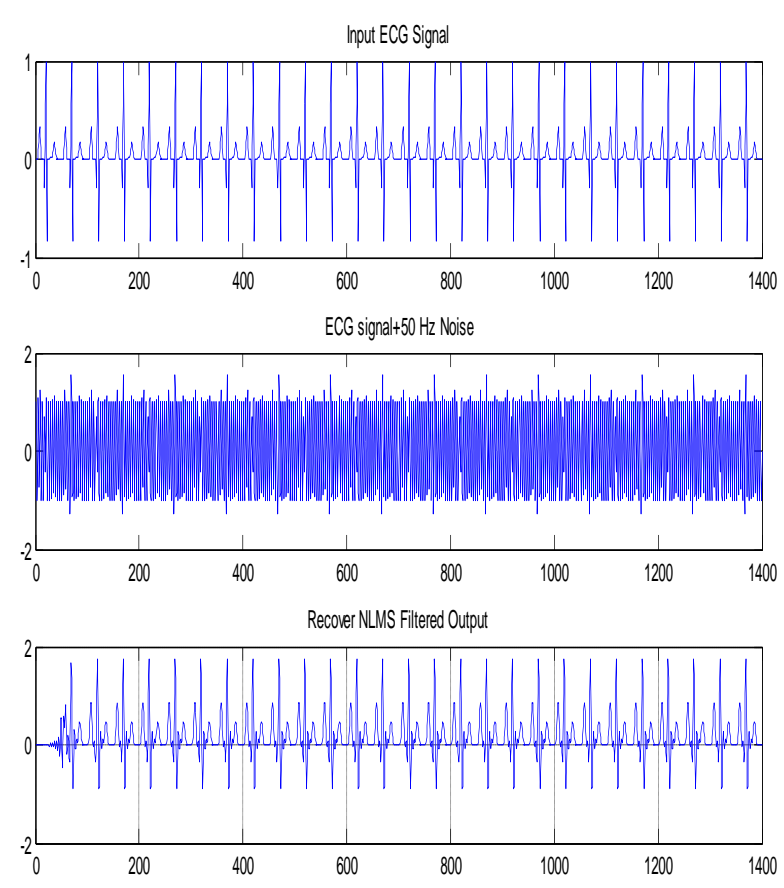

Fig. 12 NLMS algorithm where $c=0.019, \alpha=0.102$, Filter length $=15$
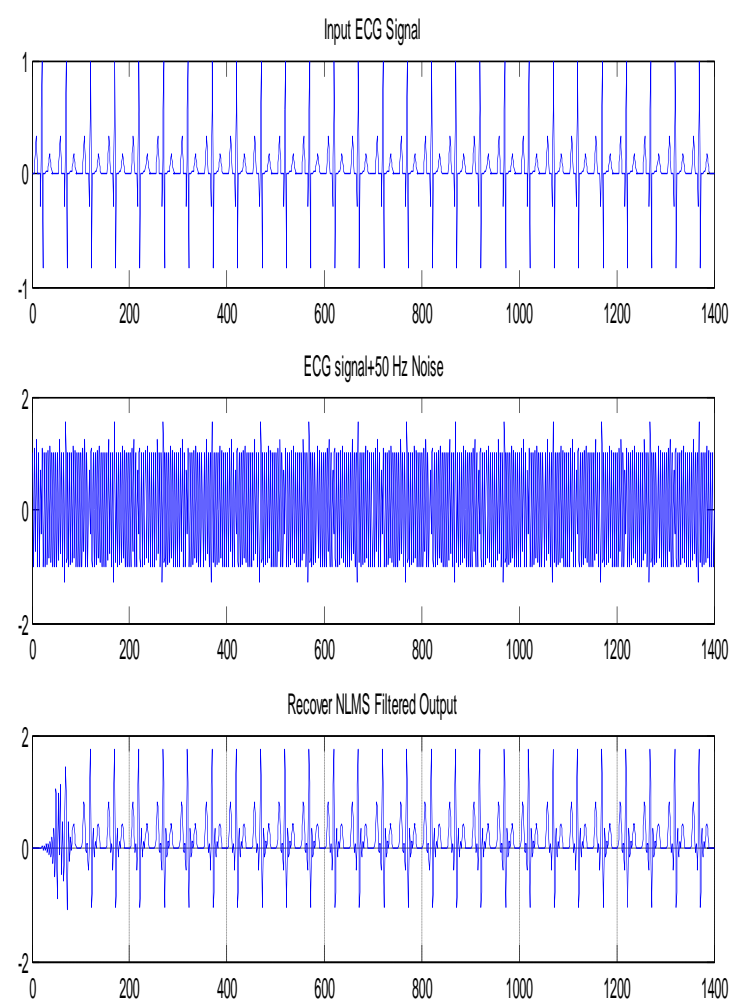

Fig. 13 NLMS algorithm where $c=0.019, \alpha=0.102$, Filter length $=25$ 
NLMS algorithm: In this case $\mathrm{c}=0.019, \alpha=0.102$, Filter length is 40 and 1400 iterations in Fig. 14 shown given below.
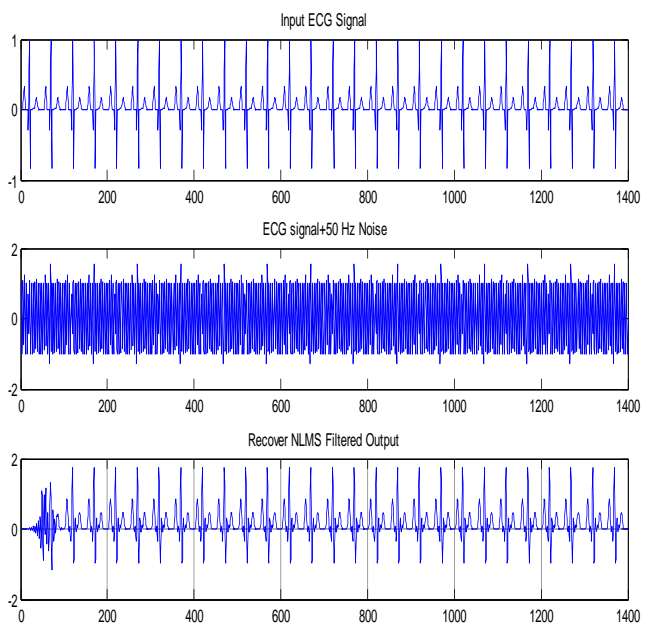

Fig. 14 NLMS algorithm where $c=0.019, \alpha=0.102$, Filter length. $=40$

The objective was to optimize different adaptive filter algorithms so that we can reduce interference. In this work, different Adaptive algorithms were analyzed and compared. The parameter, LMS step size $\mu$ play important role in determine the convergence speed and stability. Convergence speed can be controlled by parameter step size $\mu$. I have plot LMS response for step size $\mu=0.05$ and $\mu=0.09$ with different filter length $15,20,25,30$. I observed that with increased filter order, accuracy increased and with increased step size convergence rate took place fast.

These results shows that the LMS algorithm has slow convergence but simple to implement and gives good results if step size is chosen correctly and is suitable for stationary environment. The merits of LMS algorithm is less consumption of memory and amount of calculation.

The NLMS algorithm changes the step-size according to the energy of input signals hence it is suitable for both stationary as well as non-stationary environment. The implementation of algorithms was successfully achieved for $\mathrm{c}=0.019, \alpha=0.102$, filter length is $15,20,25,40$ and 1400 iterations.

The noise cancellation performance of NLMS was observed consistently better when compared with LMS algorithm.

\section{REFERENCES}

[1] R.S Khandpur "Biomedical instrumentation hand book), $11^{\text {th }}$ reprint 2008 Tata McGraw -Hill publication company Limited New Delhi. ISBN-13: 978-0-070473355-3.

[2] Daniel Olguin, Frantz Bouchereau and Sergio Martinez; "Adaptive notch filter for ECG signals based on the LMS algorithm with variable step-size parameter" conference on information sciences and systems, the John Hopkins University; March 16-18, 2005.

[3] Plonsey, R. (1996). Electronic Engineer Handbook Electrocardiography and Bio-potentials (4 $4^{\text {th }}$ edition), McGraw-Hill, New York.

[4] M. K. Islam, A. N. M. M. Haque, G. Tangim, T. Ahammad, and M. R. H. Khondokar, Member, IACSIT "study and analysis of ecg signal using matlab \& labview as effective tools" International Journal of Computer and Electrical Engineering, Vol. 4, No. 3, June 2012.
[5] Hon Wan, Rongshen Fu and Li Shi, "The elimination of $50 \mathrm{~Hz}$ power line interference from ECG using a variable step size LMS adaptive filtering algorithm”. Life Science journal, Vol. 3, No. 4, pages 90 - 93. 2006.

[6] Stephen J. chapman "MATLAB programming for engineers" $3^{\text {rd }}$ Reprint Edition 2003 by Thomson asia Pte Ltd., Singapore ISBN: 981-240-606-9.

[7] Malindi, P.(2002) "Cancelling power line interference in electrophysiological signals". ECT Research Journal, 2.

[8] Widrow B. and Hoff M.E. (1960), "Adaptive switching circuits", In IREWESCON Convention Record, pp. 96104, New York.

[9] Bernard. Widrow, "Adaptive Noise Cancelling: Principles and Applications" Proceedings IEEE, vol. 63, pp. 16921716.

[10] Martens S.M.M., Mischi M., Oei, S.G. and Bergmans J.W.M. (2006), 'An improved adaptive power line interference canceller for electrocardiography', IEEE Transaction on Biomedical Engineering, Vol. 53, pp. 2220-2231.

[11] Zhang Jiashu, Tai Heng-Ming, "Adaptive Noise Cancellation Algorithm for Speech Processing”, IEEE Transactions, pp 2489-2492, 2007.

[12] Jafar Ramadhan Mohammed, "A New Simple Adaptive Noise Cancellation Scheme Based on ALE and NLMS Filter", IEEE Transactions, pp 657-662, 2007.

[13] Bertran Eduard, "A Fully Analog Adaptive-Disturbance Canceller”, IEEE Transactions, pp 1605-1609, 2007.

[14] Bai Lin,Qinye Yin, "A Modified NLMS Algorithm for Adaptive Noise Cancellation", IEEE Transactions, pp 3726-3729, 2010.

[15] Mollaei Yaghoub, "Hardware Implementation of Adaptive Filters", IEEE Transactions.

[16] Thakor N.V. and Zhu Y.S. (1991), "Applications of adaptive filtering to ECG analysis: noise cancellation and arrhythmia detection', IEEE Transaction on Biomedical Engineering, Vol. 38, No. 8, pp. 785-794.

[17] Ban-Hoe Kwan, Kok-Meng Ong and Paramesran R. (2005), 'Noise removal of ECG signals using legendre moments', 27th Annual International Conference on Engineering in Medicine and Biology Society, pp. 5627 5630.

[18] Hae-Jeong Park, Do-Un Jeong and Kwang- Suk Park (2002), 'Automated detection and elimination of periodic ECG artifacts in EEG using the energy interval histogram method', IEEE Transactions on Biomedical Engineering, Vol. 49, No. 12, pp. 1526- 1533.

[19] Barbosa P.R.B., Barbosa-Filho J., De Sa C.A.M., Barbosa E.C. and Nadal J. (2003), 'Reduction of electromyographic noise in the signal-averaged electrocardiogram by spectral decomposition', IEEE Transactions on Biomedical Engineering, Vol. 50, No. 1, pp. 114-117.

[20] G.K. Mithal, Ravi Mittal "Radio Engineering" $19^{\text {th }}$ Revised Edition Khanna publication company Limited New Delhi.

[21] S.Salivanhannan, A Vallavaraj,C Gnanapryia , $23^{\text {rd }}$ reprint 2008, “ Digital signal processing” Tata McGraw -Hill publication company Limited New Delhi.ISBN13:978-0-07-463996-2.

[22] Proakis, J.G. and Manolakis, D.G. (1996) Digital signal processing 3rd Edition, Prentice Hall.

[23] Jigram H. Shah, Jay M. Joshi, "Digital signal processing" University science press laxmi publication company Limited New Delhi. 
[24] A. K. Ziarani and A. Konrad, "A nonlinear adaptive method of elimination of power line interference in ECG signals," IEEE Trans. Biomed. Eng., vol. 49, no. 6, pp. 540-547, Jun. 2002.

[25] Suzanna M. M. Martens , Massimo Mischi, S. Guid Oei, 'An Improved Adaptive Power Line Interference Canceller for Electrocardiography' IEEE transactions on biomedical engineering, vol. 53, no. 11, November 2006.

[26] Syed Zahurul Islam, Syed Zahidul Islam, Razali Jidin, Mohd. Alauddin Mohd. Ali, "Performance Study of Adaptive Filtering Algorithms for Noise Cancellation of ECG Signal”, IEEE 2009.

[27] Mohammad Zia Ur Rahman, Rafi Ahamed Shaik, D V Rama Koti Reddy, " Adaptive Noise Removal in the ECG using the Block LMS Algorithm" IEEE-2009.

[28] Raj Kumar Thenua "Simulation and performance Analysis of adaptive filter in Noise cancellation" International Journal of Engineering Science and Technology Vol. 2(9), 2010, 4373-4378.

[29] A. Srinivasan "Adaptive echo noise elimination for speech Enhancement of Tamil letter 'zha ", International Journal of Engineering and Technology Vol.1(3), 2009, 91-97.

[30] Wu Xin, Jeffrey S. Fu, "Side lobe Suppression Using Adaptive Filtering Techniques", IEEE Transactions, pp 788-791, 2001.
[31] Abdullah Halim,Yusof Mat lkram, Shah Rizam Mohd Baki, "Adaptive Noise Cancellation: A Practical Study of the Least-Mean Square over Recursive Least-Square Algorithm”, IEEE transactions, pp 448-452, 2002.

[32] Egiazarian Karen and Georgi Iliev, "Adaptive System for Noise Cancellation in Wireless Communications", IEEE Transactions, pp 273-276, 2004.

[33] Jardins T. D. (2002). Cardiopulmonary Anatomy Physiology (4th ed.).

[34] R.H. Kwong and E.W. Johnston, "A variable step size LMS algorithm,” IEEE Trans, pp. 1633-1642, 1992.

[35] Mihov, G. (2011) "Subtraction procedure for removing power line interference from ECG: Dynamic threshold linearity criterion for interference suppression". The 4th Interna- tional Conference on Biomedical Engineering and Informatics (BMEI), Sofia, 15-17 October 2011.

[36] Aung Soe Khaing and Zaw Min Naing "Quantitative Investigation of Digital Filters in Electrocardiogram with Simulated Noises" International Journal of Information and Electronics Engineering, Vol. 1, No. 3, November 2011.

[37] Aung Soe Khaing and Zaw Min Naing "Quantitative Investigation of Digital Filters in Electrocardiogram with Simulated Noises" International Journal of Information and Electronics Engineering, Vol. 1, No. 3, November 2011. 